\title{
Factors associated with the blood pressures of children born to women who were hypertensive during pregnancy
}

\author{
M K OUNSTED, J M COCKBURN, V A MOAR, AND C W G REDMAN \\ Departments of Paediatrics and Obstetrics and Gynaecology, University of Oxford, John Radcliffe \\ Hospital, Oxford
}

SUMMARY At age $7 \cdot 5$ years the supine blood pressures of 216 children born to women who had been hypertensive during pregnancy were recorded. No associations were found between the blood pressures of the children and their mothers. The blood pressures of children whose mothers received methyldopa during pregnancy did not differ from those of children whose mothers had no specific treatment. Four boys whose mothers had taken methyldopa for more than 150 days had significantly lower systolic and diastolic pressures than those in whom the treatment had been of shorter duration. Significant findings from multiple regression analyses were: positive associations between boys' systolic and diastolic pressures and current weight, and diastolic pressure and maternal weight; negative associations between boys' systolic and diastolic pressures and birthweight; and a positive association between girls' systolic pressure and current weight.

The relation between anthropometric and maturaion variables and blood pressure in childhood has been well documented. ${ }^{1-3}$ Genetic factors are important, ${ }^{4}$ and associations between the mothers' condition during pregnancy and their offspring's blood pressures have also been reported..$^{5-7}$ Most studies concentrate on only one of these aspects, and little or no account is taken of other variables which may indirectly affect the findings. Sex differences, also, are rarely sought.

In a prospective study of the effect of specific treatment on maternal hypertension the women were enrolled early, and their pregnancies thereafter were monitored in depth. The children were examined at birth and followed up to the age of 7.5 years. It has therefore been possible to evaluate the children's blood pressures in respect of their own somatic measures and those of their mothers, and to look for associations with other pregnancy and perinatal factors in the same high risk sample.

\section{Patients and methods}

The mothers of these children were participating in a large, controlled trial of the treatment of maternal hypertension with methyldopa during pregnancy.
The criterion was a systolic or diastolic pressure equal to or exceeding 140 or $90 \mathrm{~mm} \mathrm{Hg}$, respectively, on two occasions separated by at least 24 hours. The average gestational age at entry was 21 weeks. Thereafter blood pressure was recorded weekly. Full details of the selection and management of the patients have been given in the original paper on fetal outcome. ${ }^{8}$ Some patients were excluded from the randomised trial because of 'severe' hypertension (170/110 $\mathrm{mm} \mathrm{Hg}$ or more) at presentation, or because they were already on hypotensive treatment, or had other medical or obstetric complications. Their pregnancies were monitored in the same way as the rest, however, and their surviving infants were included in the follow up studies from birth. Data are analysed on 216 children (121 boys and 95 girls) whose mothers had blood pressures recorded by their general practitioner (GP) before 20 weeks' gestation. Maximum maternal blood pressures were also coded in every case.

At the age of 7.5 years the children were all examined by the same person (JC) in a quiet room at school. After a lengthy developmental assessment, and measurements of weight, height, and head circumference, the child was asked to lie down on the floor on a pillow and blanket. An interval of 
five minutes was given to allow the child to relax. During this time an explanation was given about what was involved in blood pressure measurements, any relevant questions were answered, and nervousness abated. The appropriate sized paediatric sleeve was then wound round the right arm, and the blood pressure was recorded with a random-zero sphygmomanometer ${ }^{9}$ using a stethoscope with a paediatric head. The diastolic reading was Korotkoff phase IV.

Analyses of variance, regressions, and correlation coefficients were used to analyse the data where relevant.

\section{Results}

Eleven maternal, pregnancy, and perinatal variables were taken and these were analysed in relation to the first GP and maximum maternal systolic and diastolic pressures. No associations were found with first GP pressures for any of the variables. No differences in maximum systolic or diastolic pressures were found according to the sex of the infant, smoking, social class, parity, or maternal weight. Factors for which significant differences were found between the mean values for maximum systolic or diastolic pressures are shown in Table 1. Women aged 35 years or more had a higher systolic pressure, and those who received methyldopa had a lower diastolic pressure than those who did not. Women who developed pre-eclampsia ${ }^{10}$ had higher systolic and diastolic pressures than those who were hypertensive only. Delivery by elective caesarean section was associated with a higher systolic pressure than delivery by emergency section, or per vaginam; and systolic and diastolic pressures were higher when the babies were preterm or small for dates.

Boys had slightly higher systolic pressure (mean(SD), 105.2 (9.7) $\mathrm{mm} \mathrm{Hg}$ ) and diastolic pressure $(63.9(9.5) \mathrm{mm} \mathrm{Hg})$ than girls $(104.2(8.8)$ and $62.4(9.1) \mathrm{mm} \mathrm{Hg}$ ) at the age of 7.5 years. Comparable analyses with those done above showed no associations with any of the variables with the exception of maternal weight-children born to women weighing more than $100 \mathrm{~kg}$ had a higher mean diastolic pressure than the rest $(\mathrm{P}<0.05)$.

Correlations between the children's blood pressures and their mothers' first GP and maximum pressures were all very close to zero. Fifty four $(25 \%)$ of the women were normotensive (systolic pressure less than 140 and diastolic pressure less than $90 \mathrm{~mm} \mathrm{Hg}$ ) during early pregnancy. When their children were compared with the rest both the mean systolic and diastolic pressures were lower, but in neither case was the difference significant. The children were then divided into four groups according to their mothers' systolic and diastolic pressure profiles: (1) low or moderate throughout pregnancy; (2) low early, high later; (3) high early, low later; (4) high throughout pregnancy. No differences were found in the mean systolic or diastolic pressures of the children at 7.5 years between any of these four groups.

The mean systolic and diastolic pressures of 119 children whose mothers received methyldopa (mean (SD), $104.9(9.0) / 63.7(9.3) \mathrm{mm} \mathrm{Hg}$ ) and 97 children whose mothers had no specific treatment (104.9 $(9.8) / 63.0(9.6) \mathrm{mm} \mathrm{Hg})$ were very similar. When children whose mothers received methyldopa were divided according to the duration of drug treatment

Table 1 Maximum maternal blood pressures ( $\mathrm{mm} \mathrm{Hg}$ ) and associated variables (values, mean (SD))

\begin{tabular}{|c|c|c|c|c|c|}
\hline $\begin{array}{l}\text { Maternal age } \\
\text { Systolic } \\
\text { Diastolic }\end{array}$ & $\begin{array}{rr}<25 y & (n=52) \\
149 \cdot 3 & (15 \cdot 0) \\
99 \cdot 1 & (11.9)\end{array}$ & $\begin{array}{cc}25-34 y & (n=128) \\
147.8 & (15.5) \\
95.5 & (11.5)\end{array}$ & $\begin{array}{rr}\geqslant 35 y & (n=18) \\
155 \cdot 4 & (16 \cdot 3) \\
99.6 & (12 \cdot 8)\end{array}$ & & $\begin{array}{l}F \\
3 \cdot 5^{*} \\
2 \cdot 8\end{array}$ \\
\hline $\begin{array}{l}\text { Methyldopa } \\
\text { Systolic } \\
\text { Diastolic }\end{array}$ & $\begin{array}{ll}\text { Yes }(n=119) \\
148 \cdot 0 \quad(17 \cdot 0) \\
95 \cdot 4 \quad(12 \cdot 2)\end{array}$ & $\begin{array}{l}\text { No }(n=99) \\
151.3 \quad(13.9) \\
99.0 \quad(11.4)\end{array}$ & & & $\begin{array}{l}2 \cdot 5 \\
5 \cdot 1^{*}\end{array}$ \\
\hline $\begin{array}{l}\text { Pre-eclampsia } \\
\text { Systolic } \\
\text { Diastolic }\end{array}$ & $\begin{array}{l}\text { Yes }(n=48) \\
155 \cdot 4 \quad(16 \cdot 6) \\
102 \cdot 0 \quad(11 \cdot 3)\end{array}$ & \begin{tabular}{ll}
\multicolumn{3}{c}{ No $(n=161)$} \\
147.9 & $(15 \cdot 4)$ \\
96.0 & $(11 \cdot 8)$
\end{tabular} & & & $\begin{array}{l}8 \cdot 6^{* *} \\
9 \cdot 6^{* *}\end{array}$ \\
\hline $\begin{array}{l}\text { Delivery } \\
\text { Systolic } \\
\text { Diastolic }\end{array}$ & $\begin{array}{l}\text { Spontaneous }(n=117) \\
148 \cdot 5 \quad(15 \cdot 6) \\
96 \cdot 4 \quad(12 \cdot 3)\end{array}$ & $\begin{array}{ll}\text { Instrumental }(n=55) \\
148 \cdot 1 \quad(12 \cdot 4) \\
95.6 \quad(8 \cdot 8)\end{array}$ & $\begin{array}{ll}\text { Elective } & C S(n=23) \\
158 \cdot 0 \quad(21 \cdot 7) \\
103 \cdot 3 \quad(14 \cdot 6)\end{array}$ & \begin{tabular}{l}
\multicolumn{2}{c}{ Emergency CS $(n=23)$} \\
$149.6 \quad(14.4)$ \\
$97.8 \quad(12.3)$
\end{tabular} & $\begin{array}{l}2 \cdot 7^{*} \\
2 \cdot 6\end{array}$ \\
\hline $\begin{array}{l}\text { Gestation } \\
\text { Systolic } \\
\text { Diastolic }\end{array}$ & $\begin{array}{ll}<37 \text { weeks }(n=26) \\
158 \cdot 3 \quad(23 \cdot 8) \\
103 \cdot 7 & (17 \cdot 1)\end{array}$ & $\begin{array}{l}\geqslant 37 \text { weeks }(n=192) \\
148 \cdot 3 \quad(13 \cdot 9) \\
96 \cdot 2 \quad(10 \cdot 8)\end{array}$ & & & $\begin{array}{l}9 \cdot 6^{* *} \\
9 \cdot 4^{* *}\end{array}$ \\
\hline $\begin{array}{l}\text { Birthweight for } \\
\text { gestational age }\end{array}$ & $<10$ th centile $(n=19)$ & $\geqslant 10$ th centile $(n=199)$ & & & \\
\hline $\begin{array}{l}\text { Systolic } \\
\text { Diastolic }\end{array}$ & $\begin{array}{ll}160 \cdot 0 & (20 \cdot 5) \\
107 \cdot 1 & (14 \cdot 1)\end{array}$ & $\begin{array}{rr}148 \cdot 5 & (14 \cdot 9) \\
96 \cdot 1 & (11 \cdot 3)\end{array}$ & & & $\begin{array}{l}9 \cdot 7^{* *} \\
15 \cdot 8^{* * *}\end{array}$ \\
\hline
\end{tabular}

${ }^{*} \mathrm{P}<0.05 .{ }^{* *} \mathrm{P}<0 \cdot 01 .{ }^{* * *} \mathrm{P}<0.001 . \mathrm{CS}=$ caesarean section. 
significant differences were found for the boys (Table 2). Those whose mothers were treated for more than 150 days had lower systolic pressure $(\mathrm{t}=2.58, \mathrm{P}<0.05)$ and diastolic pressure $(\mathrm{t}=3.77$ $\mathrm{P}<0.001)$ than the rest. No differences were found according to the total amount of methyldopa taken.
When the children were divided into three groups according to their blood pressures no differences were found in mean height or head circumference, but significant differences were found among boys for weight and weight for height (Table 3 ); those in the high systolic and diastolic pressure groups were

Table 2 Children's blood pressures ( $\mathrm{mm} \mathrm{Hg}$ ) according to duration of treatment and total amount of methyldopa taken ${ }^{\dagger}$ (values, mean ( $S D)$ no (in italics))

\begin{tabular}{|c|c|c|c|c|c|c|c|c|c|c|c|c|c|}
\hline & \multicolumn{13}{|c|}{ Duration of treatment (days) } \\
\hline & \multicolumn{3}{|l|}{$\leqslant 50$} & \multicolumn{3}{|c|}{$51-100$} & \multicolumn{3}{|c|}{$101-150$} & \multicolumn{3}{|l|}{$>150$} & \multirow[t]{2}{*}{$F$} \\
\hline \multicolumn{13}{|l|}{ Systolic } & \\
\hline Boys & $110 \cdot 5$ & $(12 \cdot 4)$ & 4 & $104 \cdot 7$ & $(7 \cdot 4)$ & 24 & $106 \cdot 6$ & $(9 \cdot 8)$ & 20 & $94 \cdot 5$ & $(3 \cdot 4)$ & 4 & $2 \cdot 8^{*}$ \\
\hline Girls & $103 \cdot 1$ & $(4 \cdot 9)$ & 7 & $105 \cdot 5$ & $(9.8)$ & 11 & $103 \cdot 1$ & $(7 \cdot 1)$ & 15 & $103 \cdot 4$ & $(11 \cdot 6)$ & 9 & $0 \cdot 2$ \\
\hline \multicolumn{14}{|l|}{ Diastolic } \\
\hline Boys & $64 \cdot 0$ & $(12 \cdot 1)$ & 4 & $64 \cdot 6$ & $(7 \cdot 2)$ & 24 & $67 \cdot 1$ & $(7 \cdot 6)$ & 20 & $50 \cdot 5$ & $(7 \cdot 2)$ & 4 & $5 \cdot 1^{* *}$ \\
\hline \multirow[t]{3}{*}{ Girls } & $62 \cdot 0$ & $(4 \cdot 6)$ & 7 & $64 \cdot()$ & $(11 \cdot 3)$ & 11 & $62 \cdot 5$ & $(8 \cdot 3)$ & 15 & $60 \cdot 3$ & $(13 \cdot 3)$ & 9 & $0 \cdot 2$ \\
\hline & \multicolumn{13}{|c|}{ Total amount of methyldopa taken $(\mathrm{g})$} \\
\hline & $<100$ & & & $100-1$ & 19.9 & & $150-1$ & 9.9 & & $\geqslant 200$ & & & $F$ \\
\hline \multicolumn{14}{|l|}{ Systolic } \\
\hline Boys & $104 \cdot 7$ & $(9 \cdot 8)$ & 15 & $107 \cdot 2$ & $(8 \cdot 2)$ & 23 & $103 \cdot 3$ & $(11 \cdot 5)$ & 8 & $100 \cdot 7$ & $(5 \cdot 6)$ & 6 & 1.07 \\
\hline Girls & $101 \cdot 5$ & $(7 \cdot 0)$ & 15 & $106 \cdot 0$ & $(12 \cdot 0)$ & 8 & $105 \cdot 6$ & $(6 \cdot 8)$ & 9 & 103.9 & $(9 \cdot 0)$ & 10 & 0.67 \\
\hline \multicolumn{14}{|l|}{ Diastolic } \\
\hline Boys & $64 \cdot 8$ & $(7 \cdot 6)$ & 15 & $65 \cdot 0$ & $(7.9)$ & 23 & $64 \cdot 8$ & $(13 \cdot 8)$ & 8 & $61 \cdot 0$ & $(6 \cdot 5)$ & 6 & 0.34 \\
\hline Girls & 60.9 & $(7.9)$ & 15 & $63 \cdot 3$ & $(15 \cdot 6)$ & 8 & $63 \cdot 3$ & $(8 \cdot 2)$ & 9 & 62.9 & $(8 \cdot 7)$ & 10 & $0 \cdot 16$ \\
\hline
\end{tabular}

†Children whose mothers had no specific treatment are excluded. ${ }^{*} \mathrm{P}=0 \cdot\left(05,{ }^{* *} \mathrm{P}<0 \cdot 01\right.$.

Table 3 Associations between the children's blood pressure ( $\mathrm{mm} \mathrm{Hg}$ ) and other factors (values, mean (SD))

\begin{tabular}{|c|c|c|c|c|c|c|c|c|c|}
\hline $\begin{array}{l}\text { Systolic (boys:girls) } \\
\text { Diastolic (boys:girls) }\end{array}$ & \multicolumn{2}{|c|}{$\begin{array}{l}\text { Group I (low) } \\
(14: 15) \\
(20: 16)\end{array}$} & \multicolumn{2}{|c|}{$\begin{array}{l}\text { Group } 2 \text { (average) } \\
(89: 70) \\
(86: 72)\end{array}$} & \multicolumn{2}{|c|}{$\begin{array}{l}\text { Group } 3 \text { (high) } \\
(18: 10) \\
(15: 7)\end{array}$} & \multirow[t]{2}{*}{$F$} & \multicolumn{2}{|c|}{ Correlation } \\
\hline \multicolumn{9}{|l|}{ Weight $(k g)$} & \\
\hline Systolic: Boys & $24 \cdot 0$ & $(4 \cdot 3)$ & $24 \cdot 5$ & $(3 \cdot 4)$ & $27 \cdot 1$ & $(7 \cdot 1)$ & $3 \cdot 0^{+}$ & $0.21^{*}$ & \\
\hline Girls & $24 \cdot 3$ & $(4 \cdot 2)$ & $24 \cdot 6$ & $(4 \cdot 2)$ & $26 \cdot 6$ & (3.9) & $1 \cdot 1$ & $0 \cdot 27^{* *}$ & $0 \cdot 23^{* * *}$ \\
\hline Diastolic: Boys & $23 \cdot 6$ & $(3.9)$ & $24 \cdot 7$ & $(3 \cdot 3)$ & $27 \cdot 6$ & $(7 \cdot 8)$ & $4 \cdot 3^{*}$ & $0.25^{* *}$ & \\
\hline Girls & $23 \cdot 5$ & $(2 \cdot 6)$ & 24.9 & $(4 \cdot 5)$ & $26 \cdot 8$ & $(2 \cdot 8)$ & 1.5 & 0.10 & $0 \cdot 19^{* *}$ \\
\hline \multicolumn{10}{|l|}{ Weight/height 2} \\
\hline \multirow[t]{2}{*}{ Systolic: } & $1 \cdot 54$ & $(0 \cdot 17)$ & 1.55 & $(0 \cdot 18)$ & $1 \cdot 70$ & $(0 \cdot 32)$ & $6.92^{* *}$ & $0 \cdot 25^{* *}$ & \\
\hline & 1.54 & $(0 \cdot 19)$ & 1.57 & $(0 \cdot 21)$ & $1 \cdot 66$ & $(0.22)$ & $1 \cdot 12$ & $0.25^{*}$ & $\left(0 \cdot 25^{* * *}\right.$ \\
\hline \multirow{2}{*}{ Diastolic: } & $1 \cdot 51$ & $(0 \cdot 16)$ & $1 \cdot 55$ & $(0 \cdot 16)$ & 1.72 & $(0.39)$ & $5 \cdot 48^{* *}$ & $0.26^{* *}$ & \\
\hline & 1.51 & $(0 \cdot 10)$ & 1.58 & $(0 \cdot 23)$ & 1.62 & $(0.09)$ & 0.81 & $0 \cdot 05$ & $0 \cdot 17^{*}$ \\
\hline \multicolumn{10}{|l|}{ Birthweight $(\mathrm{kg})$} \\
\hline \multirow[t]{2}{*}{ Systolic: } & $3 \cdot() 4$ & $(0 \cdot 63)$ & $3 \cdot 22$ & $(0.51)$ & $2 \cdot 78$ & $(0 \cdot 68)$ & $5 \cdot 0^{* *}$ & $-0 \cdot 21^{*}$ & \\
\hline & $3 \cdot 07$ & $(0.71)$ & 3.05 & $(0.48)$ & $2 \cdot 82$ & $(0.43)$ & 1.0 & $-0 \cdot 00$ & $-0 \cdot 12$ \\
\hline \multirow{2}{*}{ Diastolic: } & 3.07 & $(0 \cdot 52)$ & $3 \cdot 20$ & $(0.54)$ & $2 \cdot 87$ & $(0.73)$ & $2 \cdot 5$ & -0.08 & \\
\hline & $3 \cdot 05$ & $(0.71)$ & 3.06 & $(0.47)$ & $2 \cdot 64$ & $(0.43)$ & $2 \cdot 3$ & -0.09 & $-0 \cdot 08$ \\
\hline \multicolumn{10}{|l|}{ Gestation (days) } \\
\hline Systolic: & 264 & $(10)$ & 268 & (9) & 262 & (16) & $2 \cdot 8$ & -0.17 & \\
\hline Girls & 263 & (17) & 269 & (6) & 263 & (9) & $3 \cdot 6^{*}$ & 0.08 & \}$-0 \cdot(08$ \\
\hline \multirow[t]{2}{*}{ Diastolic: } & 266 & (8) & 268 & (10) & 262 & (17) & 1.8 & -0.05 & \\
\hline & 265 & (14) & 268 & (10) & 264 & (8) & $0 \cdot 8$ & $0 \cdot 04$ & $-0 \cdot(02$ \\
\hline \multicolumn{10}{|l|}{ Maternal weight $(\mathrm{kg})$} \\
\hline \multirow[t]{2}{*}{ Systolic: } & $64 \cdot 2$ & $(10 \cdot 0)$ & $65 \cdot 4$ & $(12 \cdot 3)$ & $71 \cdot 4$ & $(16 \cdot 9)$ & $1 \cdot 7$ & 0.09 & \\
\hline & $63 \cdot 5$ & $(12 \cdot 6)$ & $65 \cdot 2$ & $(13.9)$ & $69 \cdot()$ & $(16.9)$ & 0.5 & $0 \cdot 15$ & $0 \cdot 11$ \\
\hline \multirow[t]{2}{*}{ Diastolic: } & $63 \cdot 1$ & $(10 \cdot 3)$ & $65 \cdot 6$ & $(12 \cdot 2)$ & $73 \cdot 5$ & $(17 \cdot 9)$ & $3 \cdot 0^{+}$ & $0.25^{* *}$ & \\
\hline & $59 \cdot 3$ & $(8 \cdot 8)$ & 66.4 & $(14 \cdot 5)$ & 67.9 & $(15 \cdot 8)$ & 1.9 & 0.16 & $*$ \\
\hline
\end{tabular}

${ }^{+} \mathrm{P}=0 \cdot 05,{ }^{*} \mathrm{P}<0 \cdot 05,{ }^{* *} \mathrm{P}<0 \cdot 01,{ }^{* * *} \mathrm{P}<0 \cdot 001$

The criteria for the three groups were:

Systolic blood pressure $(\mathrm{mm} \mathrm{Hg}) 1 \leqslant 95,296-113,3 \geqslant 114$

Diastolic blood pressure $(\mathrm{mm} \mathrm{Hg}) 1 \leqslant 54,255-72,3 \geqslant 73$. 
(relatively) heavier than those with average or low pressures. Although a similar trend was present among girls, the differences were not significant. In general, negative correlations were found between blood pressure and birthweight; and significant differences were found for systolic pressure among boys, those in the highest group having the lowest mean birthweight. Associations with gestational age are less clear. For three out of four recordings, children in the highest blood pressure groups had the shortest gestation; but in each case gestational age was longer in the average blood pressure groups than in the low group. In all recordings the mothers of children with the lowest blood pressure were the lightest and those with the highest were heaviest; and the differences according to diastolic pressure for boys were significant.

Weight and weight for height were highly correlated $(\mathrm{r}=0.90)$, so also were birthweight and gestation $(r=0.52)$. Multiple regression analyses of the factors shown in Table 3 were therefore done including either weight or weight for height, and either birthweight or gestation. Significant findings were as follows: (1) positive associations between boys' systolic and diastolic pressures and weight or weight for height, and also between diastolic pressure and maternal weight; (2) negative associations between boys' systolic and diastolic pressures and birthweight or gestation; (3) a positive association between girls' systolic pressure and weight or weight for height. No clear patterns emerged when correlations of different factors with blood pressure at $7 \cdot 5$ years were adjusted for confounding between variables.

\section{Discussion}

The mothers of all the children in this study had been hypertensive during pregnancy. Most had been randomly allocated to treatment with methyldopa or no specific hypotensive treatment. All the women and their children had optimal antenatal and perinatal care. High maternal pressures were associated with superimposed pre-eclampsia, delivery by elective caesarean section, and the birth of preterm or small for dates babies. These factors are likely to be interrelated since obstetric intervention to expedite delivery before 37 weeks' gestation is more likely to occur when there is severe hypertension associated with intrauterine growth retardation.

As expected, mothers who received specific treatment had a lower maximum blood pressure, but no differences were found in their children. ${ }^{11}$ Four boys whose mothers took methyldopa for more than 150 days had a particularly low blood pressure. They were all in good health, and their birthweights, childhood weights, and those of their mothers did not differ from the rest of the sample. This finding may have occurred by chance, but it is noteworthy that the girls who had undergone a comparable length of 'treatment' in utero were not similarly affected.

Two studies have reported raised blood pressures among children born to women who were hypertensive during pregnancy. ${ }^{6} 7$ In neither case, however, was the association shown to be a direct one. In a prospective study, ${ }^{7}$ blood pressure before the onset of pregnancy was significantly higher in women who subsequently developed pre-eclampsia than among those who did not. Female offspring of the former had higher blood pressure than those of non-preeclamptic mothers. The authors considered their data compatible 'with a sex-linked subset of essential hypertension'. In Kotchen et al's study ${ }^{6}$ hypertensive women were heavier than normotensive women and, in addition to blood pressure, high correlations were found between the children's and mother's current weight. These are likely to have been the confounding variables. No associations were found between maternal hypertension in pregnancy and high blood pressure at 7 years in a large cohort of children born in Dunedin. ${ }^{2}$ We also undertook a large number of analyses compounding the early GP and maximum maternal blood pressure in order to investigate the effects of long term (versus short), and very severe (versus moderate) hypertension during pregnancy on the children's blood pressures at 7.5 years. No differences emerged.

Negative associations between birthweight and blood pressure have recently been reported for children aged 7 and 10 years born, respectively, in Dunedin ${ }^{2}$ and Aberdeen. ${ }^{12}$ Cater and Gill ${ }^{12}$ thought this variation was 'unlikely to be important clinically.' Simpson et $a l^{2}$ suggested that perinatal and fetal factors might be 'a common factor in the genesis of low birthweight and later high BP'. None were identified in our study; and the explanation may lie in the first few months after birth. There is very little correlation between blood pressure at birth and later years. ${ }^{13}$ 'Tracking' does not become established until about 6 to 12 months. ${ }^{14}{ }^{15}$ Blood pressure is linked to weight, and there is a negative correlation between birthweight and postnatal weight gain. ${ }^{16}$ Most healthy infants of low birthweight have an accelerated growth spurt during their first six months of life. ${ }^{17} 18$ If this were accompanied by a comparable spurt in blood pressure then the values would be set on a higher than expected plane when tracking becomes established.

Associations have been found between children's blood pressures at 7.5 years and their mother's 
weight, duration of methyldopa treatment, birthweight, and current weight. For each variable the relations were stronger in boys than girls. These may be due, in part, to the greater vulnerability of the male sex. Since the organism's response to an environmental influence is affected by the maturational state achieved when this occurs, they may also be associated with gender differences in the patterns of growth and development during fetal and early postnatal life. ${ }^{18}$ The specific age at which the children were examined may also have contributed to the findings. It was formerly thought that between 6 and 9 years growth and development proceeded fairly steadily, but recent studies have drawn attention to a mid-growth spurt in weight ${ }^{19}$ and a peak in diastolic pressure increase ${ }^{13}$ at this time. Both these changes occur earlier in girls than boys. Growth and maturation are not smooth processes, and differences between the sexes become more overt when step-function changes occur. Many investigators still treat children as a homogeneous population. At all ages gender differences should not only be taken account of, but actively sought.

We thank Andy Scott for statistical advice. This work is supported by a Medical Research Council programme grant. Merck, Sharp and Dohme also gave financial support.

\section{References}

${ }^{1}$ Richey HG. The blood pressure in boys and girls before and after puberty. Am J Dis Child 1931;42:1281-330.

2 Simpson A, Mortimer JG, Silva PA, Spears G, Williams S. In: Onesti G, Kim KE, eds. Hypertension in the young and old. New York: Grune and Stratton, 1981;153-63.

3 Voors AW, Webber LS, Frerichs RR, Berenson GS. Body height and body mass as determinants of basal blood pressure in children - the bogalusa heart study. Am J Epidemiol 1977;106: 101-8.

4 Zinner SH, Levy PS, Kass EH. Familial aggregation of blood pressure in childhood. $N$ Engl J Med 1971;284:401-4.

5 Syklo M. Epidemiologic patterns of blood pressure in children. Epidemiol Rev 1979;1:143-69.
${ }^{6}$ Kotchen JM, Kotchen TA, Cottrill CM, Guthrie GP, Somes G. Blood pressures of young mothers and their first children 3-6 years following hypertension during pregnancy. J Chronic Dis 1979;32:653-9.

7 Langford HG, Watson RL. Pre-pregnant blood pressure, hypertension during pregnancy, and later blood pressure of mothers and offspring. Hypertension 1980;Suppl 1:1130-3.

${ }^{8}$ Redman CWG, Beilin LJ, Bonnar J, Ounsted MK. Fetal outcome in trial of antihypertensive treatment in pregnancy. Lancet 1976;ii:753-6.

9 Wright BM, Dore CS. A random-zero sphygmomanometer. Lancet 1970;i:337-8.

10 Ounsted M, Cockburn J, Moar VA, Redman CWG. Maternal hypertension with superimposed pre-eclampsia: effects on child development at 7.5 years. Br J Obstet Gynaecol 1983;90:644-9.

" Cockburn J, Moar VA, Ounsted M, Redman CWG. Final report of study on hypertension during pregnancy: the effects of specific treatment on the growth and development of the children. Lancet 1982;i:647-9.

12 Cater J, Gill M. The follow-up study: medical aspects. In: Illsey R, Mitchell RG, eds. Low birthweight, a medical, psychological and social study. Chichester: John Wiley and Sons, 1984:191-205.

13 Katz SH, Hediger ML, Schall I, Valleroy LA. Growth and blood pressure. In: Kotchen TA, Kotchen JM, eds. Clinical approaches to high blood pressure in the young. Boston: John Wright, 1983;91-131.

${ }^{14}$ De Swiet M, Earley A, Fayers P, Shinebourne EA. An epidemiologic study of blood pressure in childhood. In: Onesti G, Kim KE, eds. Hypertension in the young and old. New York: Grune and Stratton, 1981:139-47.

15 Schachter J, Kuller LH, Perkins JM, Radin ME. Infant blood pressure and heart rate: relation to ethnic group, nutrition and electrolyte intake. Am J Epidemiol 1979;110:205-18.

10 Thomson J. Observations on weight gain in infants. Arch Dis Child 1955;30:322-7.

17 Cruise MO. A longitudinal study of the growth of low birthweight infants. Pediatrics 1973;51:322-7.

${ }^{18}$ Scott A, Moar VA, Ounsted M. Growth in the first four years: I. The relative effects of gender and weight for gestational age at birth. Early Hum Dev 1982;7:17-28.

19 Tanner JM, Cameron N. Investigation of mid-growth spurt in height, weight and limb circumference in single-year velocity data from the London 1966-1967 growth survey. Ann Hum Biol 1980;7:565-77.

Correspondence to Dr M K Ounsted, Department of Paediatrics, John Radcliffe Hospital, Oxford OX3 9DU.

Received 7 February 1985 